\title{
Construindo um dispositivo coletivo em oficinas na Saúde Mental
}

Construyendo un dispositivo colectivo en oficinas en la Salud Mental

Building a collective device in Mental Health workshops

\section{Ariana Campana Rodrigues}

\author{
Silvio Yasui \\ Universidade Estadual Paulista (UNESP), São Paulo, SP, Brasil
}

\begin{abstract}
Resumo
Este texto é um relato de experiência profissional em que se construiu coletivamente um dispositivo denominado "Planilha da Vida Ocupacional" para acompanhar e analisar a produção de trabalho de pessoas com transtornos mentais em oficinas de geração de trabalho e renda do Núcleo de Oficinas e Trabalho. Optou-se pelo percurso metodológico cartográfico para narrar essa experiência. No processo de responder a um questionamento sobre a missão do equipamento de saúde, além de refletir sobre o progresso dos oficineiros, a equipe de profissionais também produziu sentidos para o seu próprio trabalho. São apontados como frutos dessa construção a visibilidade dada ao cuidado ampliado ao oficineiro, a possibilidade de reflexão sobre o próprio trabalho, a perspectiva interdisciplinar de atuação e o amadurecimento da equipe. As discussões pretendem contribuir com a Reforma Psiquiátrica brasileira.
\end{abstract}

Palavras-chave: Saúde Mental; Reforma Psiquiátrica; Oficinas.

\begin{abstract}
This article presents an account of professional experience in which a device called "Occupational Life Worksheet" was collectively developed to monitor and analyze the work and health production of people with mental disorders during their work on employment and income generation workshops in Núcleo de Oficinas de Trabalho. To narrate this experience we opted for the cartographic method. During the process of responding to a questioning about the mission of health equipment, in addition to reflecting on the progress of the patients, the team of professionals also produced meanings for their own work. The possibility for the professional team to think about their own work, the perspective of interdisciplinary actions, the improvement of professional team and the visibility given to the patients care are results of the development process of this worksheet. The discussions aim to contribute to the Brazilian Psychiatric Reform.
\end{abstract}

Keywords: Mental Health; Psychiatric Reform; Workshops

\section{Resumen}


Este artículo presenta un relato de experiencia profesional en lo cual se construyó colectivamente un dispositivo denominado "Planilha da Vida Ocupacional" (Hoja de Cálculo de la Vida Ocupacional) para acompañar y analizar la producción de trabajo y salud de personas con trastornos mentales en talleres de generación de trabajo e ingresos del "Núcleo de Oficinas e Trabalho" (Núcleo de Talleres y Trabajo). Se optó por el recorrido metodológico cartográfico para narrar esa experiencia. En el proceso de contestar un cuestionamiento sobre la misión del equipamiento de salud, además de reflexionar sobre el progreso de los alumnos, el equipo de profesionales también produjo sentidos para su proprio trabajo. Son señalados como fruto de esa construcción la visibilidad destinada al cuidado ampliado al alumno, la posibilidad de reflexionar acerca del proprio trabajo, la perspectiva interdisciplinar de actuación y la maduración del equipo. Las discusiones tienen como objetivo contribuir con la Reforma Psiquiátrica brasileña.

Palabras-clave: $\quad$ Salud $\quad$ Mental; Reforma Psiquiátrica; Talleres.

\section{Introdução}

Com o intuito de contribuir com discussões a respeito dos desafios no enfrentamento à marginalização social do usuário da Saúde Mental na perspectiva ética da Atenção Psicossocial, que orienta as ações de tratamento pelo cuidado em liberdade e com qualidade (Amarante, 2007; Costa-Rosa \& Yasui, 2008; CostaRosa, Luzio \& Yasui, 2003), apresento, nesta narrativa, reflexões sobre o processo de construção coletiva de um dispositivo denominado "Planilha da Vida Ocupacional" (vide figuras ao final do texto). Esse dispositivo propôs tornar visível a produção de trabalho e saúde em oficinas de geração de trabalho e renda na Saúde Mental no Núcleo de Oficinas e Trabalho (NOT) do Serviço de Saúde Cândido Ferreira (SSCF), localizado em Campinas-SP. O texto a seguir é baseado num trecho da publicação (Rodrigues, 2012) em que faço um recorte de um período de minha experiência profissional como coordenadora de algumas dessas oficinas.

A proposta deste texto é narrar a construção da Planilha - como me referirei à "Planilha da Vida Ocupacional" a partir deste momento do texto - e os efeitos disso na equipe que a fez. Sobre esse modo de contar sobre o acontecido, Benjamin elucida que a "narrativa, que durante tanto tempo floresceu num meio artesão - no campo, no mar, na cidade -, é, ela própria, num certo sentido, uma forma artesanal de comunicação" (Benjamin, 2012, p. 221). Este texto escrito dá corpo, na perspectiva benjaminiana de uma comunicação artesanal, ao que foi anteriormente falado e experimentado pela equipe, tratando de uma passagem específica em se produziu coletivamente uma ferramenta para 
acompanhar e analisara produção de trabalho e a evolução dos oficineiros.

Usualmente, denominava-se "oficineiro" a pessoa em tratamento na rede de Saúde Mental pública ou privada, com diagnósticos de psicose, neurose grave e/ou dependência química, e que trabalhava no NOT. Além disso, embora o NOT fosse constituído por trabalhadores de diversas áreas (por exemplo: motorista, médica, psicólogos, terapeutas ocupacionais, nutricionistas, monitores, vendedores, técnico administrativo e de enfermagem, entre outros), aqui "equipe" se referirá apenas aos coordenadores de oficinas, a uma assistente social e a uma gerente, pois foram esses profissionais que pensaram e produziram o dispositivo em questão.

A enunciação dessa passagem de minha experiência profissional indicou que a proposta mais apropriada para respaldar este estudo seria aquela que considerasse qualitativamente o caráter processual de tal experiência (Minayo, 1993, 2005; Constantino, 2007). Para metamorfosear o processo neste texto, compus uma escrita com elementos de minhas memórias e sustentado pelo método cartográfico.

Sobre esse percurso metodológico, a escolha da cartografia foi feita porque ela permite que o pesquisador, envolvido com o tema e com o campo, possa acompanhar os acontecimentos que compõe os estudos na posição de quem participa de ambos. A cartografia contribuiu para o desenvolvimento do tema, pois permitiu que a pesquisa tivesse origem e forma no processo de trabalho da equipe da qual eu também fazia parte e em consonância com as discussões para a construção da Planilha.

$\mathrm{Na}$ proposta da cartografia, como os estudos partem de reflexões que advém dos acontecimentos e a construção do conhecimento se dá durante o próprio pesquisar com o campo e o sujeito - e não para o campo e sujeitos -, não é possível haver um caminho de pesquisa preestabelecido. O que há é uma ética balizando as ações do pesquisador e que tem a expansão da vida como parâmetro básico (Rolnik, 2014). Portanto, em cartografia, inventa-se um caminho de pesquisa sem protocolos e regras prévios, pois o "aprendizado não pode ser enquadrado numa técnica e em um conjunto de procedimentos a seguir, mas deve ser construído no próprio processo de pesquisa" (Alvarez \& Passos, 2009, p. 135).

Portanto, o "método" - palavra que vem do grego methodos e que significa "caminho para atingir um objetivo" - tem seu sentido invertido. O objetivo (metà) é o próprio caminho (hodós), ou seja, "não 
mais um caminhar para alcançar metas préfixadas (metà-hodós), mas o primado do caminhar que traça, no percurso, suas metas" (Passos \& Barros, 2009, p. 17).

Esse tipo de produção de conhecimento, por ter como premissa o envolvimento do pesquisador, não permite uma observação distante ou tampouco imparcial em relação ao tema e sujeitos. Ele nega, portanto, a neutralidade científica e a consequente impessoalidade tradicionalmente empregada no campo científico. Por esse motivo, o texto a seguir será redigido em primeira pessoa do singular.

Também não há aqui o caráter universal de um experimento, como se pretende em muitos modos de se fazer ciência, pois a investigação se constituiu pela narrativa de uma realidade local e particular vivida num determinado contexto histórico, o que implicou que tal espaço-tempo também a configuraram. Para Deleuze (1996), “o objecto, os sujeitos não são universais, mas processos singulares, [...] de subjectivação imanentes a dado dispositivo. E cada dispositivo é uma multiplicidade na qual esses processos operam em devir, distintos dos que operam noutro dispositivo (Deleuze, 1996, p. 88). Por isso, o presente relato pode servir como inspiração a certos contextos semelhantes, mas não é em si reproduzível e aplicável.

Nesse modo de pesquisar, considera-se que os dados não estão imóveis num determinado lugar para serem coletados ou descobertos; pelo contrário, os dados só existem na relação entre os sujeitos pesquisados, o campo e o pesquisador (Rolnik, 2014; Guattari \& Rolnik, 2000). Por isso, em cartografia, fala-se em criar - e não coletar - dados, e se propõe que a análise desses dados aconteça ao mesmo tempo em que eles são criados. Assim, as análises desse momento em que a equipe construiu a Planilha não foram feitas posteriormente, mas concomitante aos acontecimentos, e o relato a seguir se configura como uma narrativa que registra essas reflexões.

Para situar sobreo campo estudado, esclareço que o NOT é um equipamento de saúde que nasceu quando o SSCF ainda era um manicômio e financiado por filantropia. Ele se transformou, ao longo do tempo e com o investimento de usuários, trabalhadores e gestores em um lugar aberto, financiado pelo Sistema Único de Saúde e constituído, além do NOT, por alguns Centros de Atenção Psicossocial, Residências Terapêuticas e Centros de Convivência.

O NOT também contava com a parceria da Associação Cornélia Vlieg, que 
foi fundada em 1993 por oficineiros e funcionários do SSCF para movimentar financeira e juridicamente as oficinas (Alcântara, 2007; Cayres, Domitti, Carnevalli \& Bianchini, 2011; Onocko \& Amaral, 2002; Valentini, 2001), especialmente no que diz respeito à comercialização dos bens e serviços produzidos pelos oficineiros e suas remunerações feitas por bolsas de trabalho.

Ainda sobre os aspectos financeiros e também sobre os princípios éticos das oficinas, elas operam condizentes com os princípios da Economia Solidária, que não valoriza a competitividade, mas a colaboração entre os trabalhadores, a autogestão, as relações tendendo a serem as mais horizontais possíveis e a importância de que todos estivessem apropriados de todas as etapas de produção de um bem ou serviço (Singer, 2002; Brasil, 2005).

À época em que trabalhei no NOT, entre os anos de 2009 e 2011, havia lá cerca de trezentos oficineiros em dezessete oficinas: Agrícola-Horta, AgrícolaJardinagem, Agrícola- Limpeza Ambiental, Ladrilho Hidráulico, Construção Civil, Marcenaria, Serralheria, Cerâmica, Vitral Artesanal, Costura, Culinária-Nutrição, Mosaico, Papel Artesanal, Vela em Sousas, Vitral Plano, Gráfica e Culinária-Eventos, além do "Armazém das Oficinas", loja própria onde eram vendidos os produtos confeccionados nas oficinas.

O NOT é, ainda hoje, referência na modalidade de geração de trabalho e renda para pessoas em tratamento na Saúde Mental, pois, além da abrangência do projeto em relação a um número considerável de pessoas, ele também é um lugar em que os oficineiros podem receber cuidado em saúde, como se verá a seguir.

\section{O Processo de Construção da Planilha:} entre o Acompanhamento dos Oficineirose o Trabalho Vivo em Ato

O ponto de partida para o processo que será narrado foi uma indagação da Prefeitura Municipal de Campinas (PMC) a respeito de quantos eram os oficineiros inseridos ou reinseridos no mercado formal de trabalho pelo NOT, o que apontou para um provável desconhecimento sobre o que era e o que se fazia lá. O produto final de intensas reflexões com a intenção de responder à incompreensão e, ao mesmo tempo, provocação da PMC, foi o que nomeamos de "Planilha da Vida Ocupacional" e que será apresentada no curso deste texto. Tratava-se de um instrumento cujo objetivo era compreender mais amplamente o progresso ou não dos oficineiros em seus movimentos de 
trabalho e as consequências disso em seu tratamento e em sua qualidade de vida.

Dadas essas circunscrições iniciais, é importante esclarecer que, por ser um equipamento de saúde que conjuga concomitantemente aspectos de trabalho e de tratamento, o desenho institucional do NOT sempre foi indagado sobre seu papel e objetivos. Em 2010, quando houve essa interpelação da PMC, debruçamo-nos a pensar sobre o porquê sermos vistos pela gestão municipal como um lugar que deveria ser canal de inserção quantitativa do oficineiro no mercado. Nas entrelinhas dessa indagação, cogitamos que também havia uma questão sobre a eficácia e eficiência do equipamento de saúde, ao que respondemos afirmativamente e justificamos com informações facilmente compreensíveis e visualizáveis.

A inferência da PMC provocou muitas questões. Dentre elas, a que balizou o processo de construção da Planilha foi: por que a missão do NOT era compreendida como a de ser uma ponte para que o usuário ingressasse pela primeira vez, ou mesmo para que retornasse, ao mercado formal de trabalho? Parece que estávamos visíveis não como um lugar que tinha por finalidade gerarrenda, trabalho e saúde, mas que deveríamos oferecer condições propícias para que o oficineiro se tornasse um trabalhador fora do NOT. Se respondêssemos afirmativamente, admitiríamos uma inverdade: que nossa oferta seria a da reabilitação para o trabalho.

Apresento, a seguir, algumas reflexões sobre o caminho que foi percorrido para responder a esta questão, introduzindo elementos que pretendem contribuir com discussões atuais da Reforma Psiquiátrica (RP).

O que, inicialmente, era uma pergunta, transformou-se numa intervenção na equipe. Durante proveitosas e extensas reuniões, tivemos a ideia de fazer algo tangível, que apresentasse o NOT de modo mais claro para quem, mesmo estando na gestão, ainda não tinha referências claras sobre ele. Fizemos um produto para responder à questão endereçada e, junto a isso, problematizamos a nós próprios sobre quem éramos e para quê servíamos.

Entre os muitos debates, pensamos que lidávamos com pessoas com dificuldades de existir produtivamente no conjunto social hegemônico capitalista e refletimos sobre o que as oficinas propunham: a produção de trabalho que visava a subsistência e a autorrealização, a produção de cuidado em saúde, a valorização dos direitos humanos, o 
favorecimento de redes de convivência, entre outros.

Sobre isso, Rauter aponta que "se se deseja que as oficinas, o trabalho e a arte possam funcionar como catalisadores da construção de territórios existenciais, ou de 'mundos' nos quais os usuários possam reconquistar ou conquistar seu cotidiano" (Rauter, 2000, p. 217) é preciso que se explore outras dimensões para além do trabalho.

Galletti (2004) também ensina sobre a importância de se considerar a oficina como lugar que amplia as possibilidades de uma vida mais saudável:

As oficinas são dispositivos que, ao não se fixarem no terreno de saúde mental, invadem e transitam por outros territórios como o trabalho, a arte, a rua e a cidade, colocando a clínica em contato com a sua exterioridade. Esses projetos tornaram-se mais do que projetos de saúde; foram projetos de vida, entendendo a vida para além da simples ausência de doença, mas vida como pluralidade, como inauguração de novas possibilidades (Galletti, 2004, p. 123).
A autora define a amplitude da potência de uma oficina que se disponha a operar para além dos limites do trabalho. É um lugar onde o cuidado em saúde - que alguns técnicos referiam como “terapêutico" podia se tornar viável.

Algumas discussões inicialmente relativizaram o uso do termo "terapêutico" que, embora controverso, era presente nas narrativas de alguns oficineiros quando eles se referiam ao que a oficina significava para eles. Ao longo dos debates, a maioria da equipe assumiu esse vocábulo, desde que ele não indicasse algo relacionado à "cura", mas à "saúde". Sobre isso, Costa e Figueiredo (2008) indagam: “[...] como sustentar a geração de renda sem prejudicar o bom andamento da função terapêutica das oficinas?" (Costa \& Figueiredo, 2008, p. 9). Como se constata, essa não é uma questão que se restringe ao NOT.

Essa pergunta fundamental foi motivadora para nos assumirmos como equipe que tinha o propósito de coordenar oficinas que deveriam se basear nos elementos "gerar trabalho e renda" e "produzir saúde". Essa dobradinha era o que sustentava as práticas nas oficinas e o que parecia dar sentido aos técnicos sobre suas atuações profissionais junto aos oficineiros. 
Outro ponto a que nos detivemos foi o de que não fazíamos somente oficinas de geração de trabalho e renda, mas que estas oficinas seriam lugares de criação de modos de trabalhar que abrigassem a possibilidade do oficineiro poder produzir o bem/serviço a ser vendido, ao mesmo tempo em que ele existia como cidadão. Se antes da RP essas pessoas estavam fadadas a ocupar lugares marginais, no momento em que refletimos sobre as pontuações da PMC pudemos celebrar a possibilidade que elas estavam tendo de se afirmarem como seres humanos que poderiam gozar de direitos e deveres.

Havia nisso o reconhecimento de que o sentido do trabalho para o oficineiro não estavar estrito a exercer um cargo ou função, tampouco a aprender e desenvolver uma atividade, mas, além de tudo isso, era também e principalmente gerar cidadania e saúde. Numa sociedade em que o trabalho acarreta sofrimento, adoecimento, desprazer, propor uma modalidade de trabalho que engendrava saúde ia contra a corrente.

Em outro trecho da discussão, refletimos sobre como precisávamos aprender afazeres para além do escopo de nosso núcleo profissional. Identificamos que produzir coletivamente o funcionamento do equipamento supunha também desertar de modos preestabelecidos de conceber a saúde. O núcleo "demarcaria a identidade de uma área de saber e de prática profissional" (Campos, 2000, p. 220) com conhecimentos específicos de cada disciplina.

Identificamos que, algumas vezes, as posturas corporativistas que privilegiavam a técnica escondiam a potência do trabalhador da saúde atrás de suposições prontas e aparentemente seguras de sua categoria profissional. Era preciso atenção ao perigo de supervalorizar um saber que fosse absoluto e específico frente às demandas que uma oficina apresentava.

Para coordenar oficinas era preciso abrandar, flexibilizar e, por vezes, romper com o núcleo profissional para tornar viáveis ações de cuidado mais amplas. $\mathrm{Ou}$ seja, era preciso dar lugar ao campo dos saberes, que seria "um espaço de limites imprecisos onde cada disciplina e profissão buscariam, em outras, apoio para cumprir suas tarefas teóricas e práticas (Campos, 2000, p. 220).

Por exemplo, ser psicóloga nas oficinas era, além de escutar e olhar para o sujeito na perspectiva do cuidado psicológico, tornar viável a organização da oficina de modo a produzir bens e serviços com eficiência e uso racional do tempo, ter desenvoltura com compras e vendas, estar 
atenta às tendências da moda, atribuir preços de acordo com as oscilações do mercado, preparar estande para feira de exposições, calcular valor de bolsas, entre muitas outras atribuições que o cotidiano de trabalho demandava.

Além de estar disponível para ações como as descritas acima, era preciso ter como princípio o cuidado centrado no oficineiro e estar maleável para lidar tanto com situações que esta relação impõe, quanto com elementos que podiam ou não ser específicos da profissão. Por exemplo, na Oficina de Velas, não era raro que um ou outro oficineiro se atrapalhasse com o processo de produção de uma vela e tivéssemos que refazer inúmeras vezes com ele o caminho de derreter a parafina e controlar a temperatura do líquido, ou que eles fossem orientados com frequência sobre os locais apropriados de descarte de lixo orgânico, ou ainda, que tirassem da embalagem uma peça de madeira pintada que ainda não estava completamente seca. São memórias dos desafios de conduzir o oficineiro em seu trabalho para que ele executasse tarefas compatíveis com seus desejos e possibilidades de atuação e, ao mesmo tempo, para que isso compusesse um cuidado ampliado.

Nesta direção, a equipe não se permitiu endurecer na posição do núcleo profissional de cada integrante para responder ao que a PMC nos perguntou, transcendendo a questão ao inventar algo com o desconforto que esta provocou. A resposta argumentativa tomou concretude quando dinamizamos os efeitos do nosso investimento de cuidado aos oficineiros na confecção da tabela que denominamos de "Planilha da Vida Ocupacional", ferramenta esta que intentava expressar e apresentar a evolução ou involução do usuário da Saúde Mental quando ele se tornava também oficineiro. Não sabíamos bem os efeitos sobre aquilo tudo, mas havia qualquer coisa da ordem (ou mesmo da desordem) do desejo em conceber certa materialidade ao que era difícil de nomear e que se relacionava ao sentido do trabalho - tanto dos oficineiros, quanto da equipe.

Propomo-nos a alimentar a Planilha com dados a cada seis meses, para que quem a lesse pudesse visualizar o que determinado oficineiro produziu ao frequentar uma oficina e suas flutuações neste período. Seria a apresentação em números do que, a princípio, parecia impossível de se quantificar. A tarefa foi árdua. Muito embora lidássemos cotidianamente com cálculos para cuidar do viés financeiro das oficinas, atribuir números à produção de saúde do oficineiro para apresentarmos nosso fazer à PMC e a nós próprios foi desafiador. 
Depois de algumas reuniões em que criamos e debatemos com entusiasmo item a item da tabela, percebemos que estávamos trabalhando muito mais na tentativa de dar visibilidade política ao NOT e de atribuirmos sentidos para nosso próprio trabalho do que para responder prontamente à PMC. Por isso, a gestão nos foi providencial, já que, a partir de um questionamento aparentemente provocativo, ela nos ofertou um terreno fértil onde conseguimos plantar a semente de um processo produtivo de discussão coletiva.

Leituras Possíveis da Planilha e suas Implicações no Cuidado ao Oficineiro

Como resultado dessa jornada de discussões, o resultado foi a "Planilha da Vida Ocupacional", em que haviauma rica mistura de itens, com campos para preenchimento da identificação do oficineiro e data da avaliação, o que viabilizaria, assim, ser comparativa em relação à próxima avaliação. Os itens avaliados eram: cuidados pessoais, manejo de dinheiro, circulação, comunicação, trabalho e convivência, informações sobre lugar de origem de tratamento (o oficineiro era necessariamente encaminhado ao NOT pelo equipamento de saúde público ou privado onde se tratava, e a maioria deles vinha de CAPS III ou Álcool e Outras Drogas, ou Centros de Saúde), qual o diagnóstico psiquiátrico, se foi acolhido em "leito noite"(leitos para acolhimento noturno de pacientes vinculados aos CAPS que têm necessidade de permanecer no equipamento por algum motivo) ou se foi internado.

Os itens tinham uma breve descrição que auxiliava na avaliação. Além disso, também era possível registrar sobre aspectos sociais do oficineiro: se tinha ou não moradia (já que havia oficineiros que eram pessoas em situação de rua ou estavam hospedados em albergues públicos), se estudava, se possuía benefício social ou se pagava a Previdência Social ou outra. Essas informações nos pareceram importantes por acreditarmos que representavam parte do que se produzia no NOT, especialmente no que tange à autonomia do sujeito e ao protagonismo de sua própria vida, que são duas propostas fundamentais da RP. Acreditávamos, como ensina Giacomel (2013), que a principal tarefa do trabalhador da saúde era produzir cuidado com o usuário para que ele pudesse aumentar sua qualidade de vida.

Éramos doze coordenadores de oficinas para levantarmos as informações e preenchermos os campos das Planilhas de cerca de trezentos oficineiros. Cada item foi decomposto em alguns subitens, 
descritos de modo breve e objetivo, aos quais atribuiríamos os valores de 1 a 5 . Esperava-se, ao final do preenchimento, determinada graduação que indicaria $o$ grau de independência do oficineiro em relação ao que ele apresentava quando foi inserido nas oficinas.

\section{Associação Cornélia Vlieg/SSCF - Núcleo de Oficinas e Trabalho Planilha da Vida Ocupacional}

Usuánio Idade:

Data da avaliação:

Data de inclusão:

\begin{tabular}{|c|c|}
\hline \multirow{5}{*}{$\begin{array}{l}\text { CUIDADOS } \\
\text { PESSOAIS }\end{array}$} & Alimentaçầo \\
\hline & Higiene pessoal \\
\hline & Medicaçăo \\
\hline & Adequaçăo na percepção da aparência \\
\hline & Afazeres domésticos \\
\hline \multirow{2}{*}{$\begin{array}{c}\text { MANEJO DE } \\
\text { DINHEIRO }\end{array}$} & Reconhecimento do valor \\
\hline & Administraçăo da renda \\
\hline \multirow{3}{*}{ CIRCULAÇĀO } & Trabalho \\
\hline & Tratamento \\
\hline & Lazer \\
\hline \multirow{3}{*}{ COMUNICAÇĀO } & Leitura \\
\hline & Escrita \\
\hline & Uso do telefone \\
\hline \multirow{10}{*}{$\begin{array}{l}\text { TRABALHO E } \\
\text { CONVIVENECIA }\end{array}$} & Pontualidade \\
\hline & Assiduidade \\
\hline & Responsabilidade \\
\hline & Iniciativa \\
\hline & Produtividade \\
\hline & Capacidade de aprendizado \\
\hline & Habilidade de lidar com frustraç̧es \\
\hline & Capacidade de negociaçăo e diálogo \\
\hline & Cooperaçăo \\
\hline & $\begin{array}{l}\text { Capacidade de respeitar as decisóes grupais } \\
\text { Relacionamento interpessoal }\end{array}$ \\
\hline
\end{tabular}

Figura 1

Planilha da Vida Ocupacional (frente)

\begin{tabular}{|l|}
\hline \multicolumn{1}{|c|}{ TRATAMENTO } \\
\hline Local: \\
\hline Frequência (mensal): \\
\hline Seque o indicado PTI ( ) SIM ( ) NÃO \\
\hline Leito Noite ( $\mathrm{n}^{\circ}$ de dias): \\
\hline Internaçăo $\left(\mathrm{n}^{\circ}\right.$ de dias): \\
\hline
\end{tabular}

\begin{tabular}{|l|}
\hline \multicolumn{1}{|c|}{ ASPECTOS SOCIAIS } \\
\hline Situaçăo de moradia: \\
\hline Beneficios ( ) SIM ( ) NÃO \\
\hline Pagamento de previdência ( ) SIM ( ) NÃO \\
\hline Retomada dos estudos/capacitaçăo ( ) SIM ( ) NÃO \\
\hline
\end{tabular}

\begin{tabular}{|l|c|}
\hline AVALLAÇĀo & GRADUAC̄ĀO \\
\hline Independência (autonomia) & $5(91-100 \%)$ \\
\hline Orientaçẵo (pontual) & $4(81-90 \%)$ \\
\hline Estimulaçăo (diária) & $3(61-80 \%)$ \\
\hline Supervisăo (acompanhamento) & $2(41-60 \%)$ \\
\hline Deoende de aiuda (fazer com) & $1(20-40 \%)$ \\
\hline
\end{tabular}


Orientações de preenchimento:

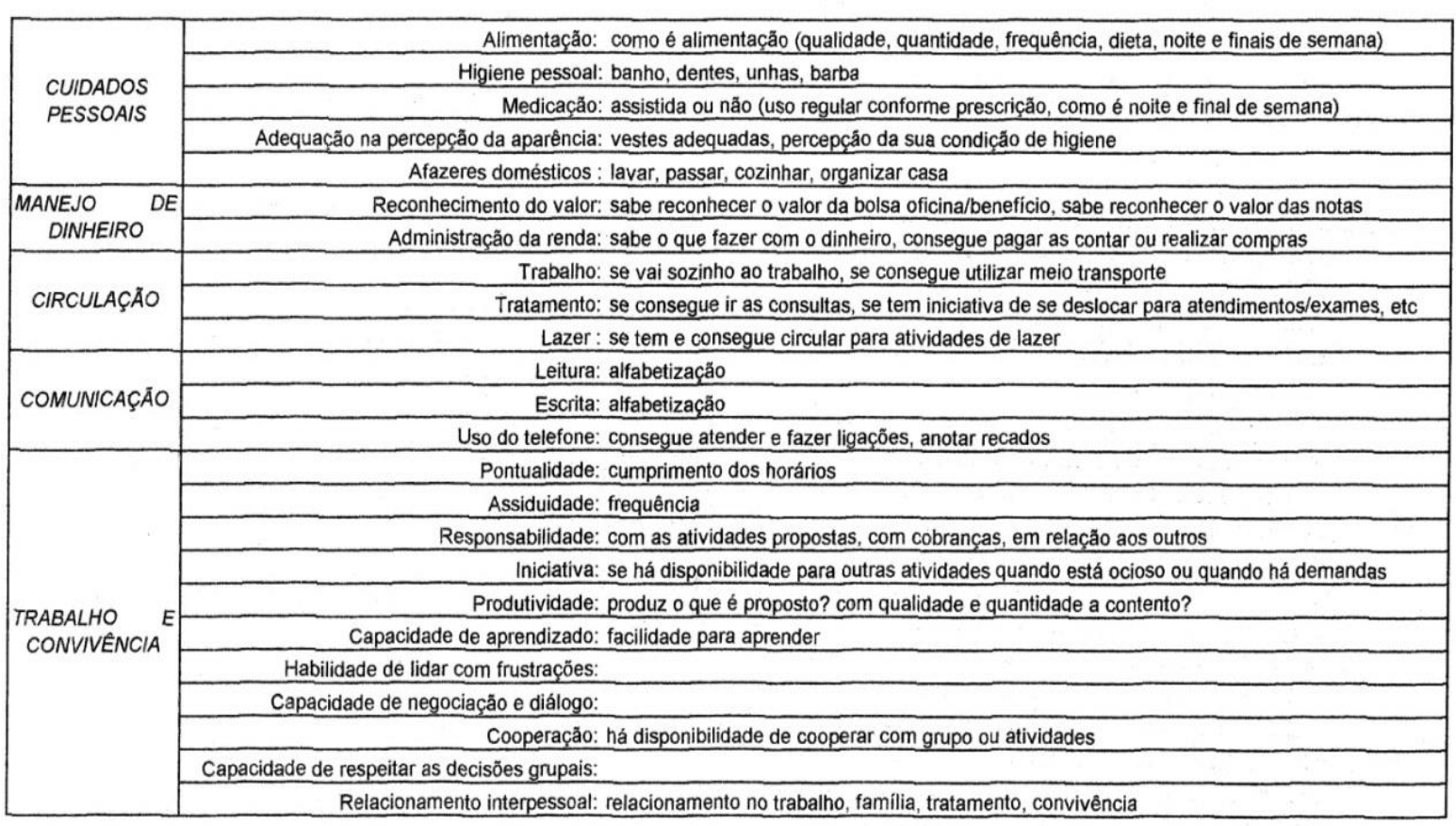

Figura 2

Planilha da Vida Ocupacional (verso)

Embora não tivéssemos feito $\mathrm{o}$ clássico caminho que muito provavelmente indicaria um profissional da ciência estatística, que seria composto de aplicação prévia do questionário para que ele fosse validado e para que os valores se tornassem os mais fidedignos possíveis do ponto de vista quantitativo, acreditávamos que a tabela, que seria preenchida pelo coordenador em parceria com o próprio oficineiro, produziria o que chamamos de "dados" que tornariam visíveis nosso trabalho. Talvez tenhamos agido com ingenuidade ao, por exemplo, indicar porcentagens de graduação na avaliação. Mas, acreditamos que esse seria uma possibilidade que nos asseguraria certo grau de credibilidade na resposta à PMC. A tabela não foi feita com o rigor matemático necessário, uma vez que a proposta não era a da seguridade numérica, mas a da visibilidade geral de nosso trabalho. A ciência matemática não foi usada, durante a tarefa de criação desse instrumento, para calcularmos dados numéricos a partir de moda, média, mediana, tendência central, entre outros.

Um dos efeitos desse processo foi termos conseguido dinamizar as conformidades e as divergências na equipe sobre quais eram os sentidos que dávamos ao nosso próprio trabalho: desde um fazer 
que pretendia produzir saúde ao oficineiro, passando por signos como convivência entre pessoas tão diferentes, respeito mútuo, implicação com os ideais da RP, e até mesmo reflexões sobre sentir-se útil socialmente e de realização pessoal. Enfatizo o termo "dinamizar" porque a intenção nunca foi equalizar modos de trabalhar, mas realçar as diferenças de olhares e posturas dos coordenadores, acreditando que isso enriqueceria nossos fazeres. As diversidades de modos de coordenar enriqueciam o NOT.

Considerávamos que o trabalho em saúde exigia investimentos que o aprimorassem. Merhy propõe que esse tipo de trabalho, que ele chama de "trabalho vivo em ato", é operado como "tecnologias de relações, de encontros de subjetividades, para além dos saberes tecnológicos estruturados, comportando um grau de liberdade significativo na escolha do modo de fazer essa produção" (Merhy, 2005, p. 48 - 49).

Foi nessa perspectiva de trabalho vivo em ato que, enquanto o discurso científico hegemônico aludia às especialidades como campo privilegiado de saber e atuação profissional, caminhamos em outro rumo ao afirmarmos que éramos uma equipe de profissionais dispostos a partilhar diferentes saberes para construirmos um único equipamento. Cada núcleo profissional diferente dialogou com seus pares, produzindo algo que se propunha interdisciplinar.

Por exemplo, o ponto que tratava dos "cuidados pessoais" tinha como subitens a "alimentação/ higiene pessoal/ medicação" que, classicamente, pertenciam ao âmbito de atuação direta dos núcleos médico e de enfermagem. Contudo, no fazer cotidiano das oficinas, sabíamos que estes três subitens eram cuidados pelos coordenadores, pelo próprio oficineiro com maior ou menor grau de autonomia, pelos oficineiros que se cuidavam entre si ou pelos monitores, que eram profissionais de nível de escolaridade médio com o conhecimento da técnica aplicada na oficina. Por exemplo: na Oficina Agrícola, os monitores eram hortelãos; na Oficina de Construção Civil, os monitores eram pedreiros ou mestres de obra; na Oficina de Culinária, os monitores eram cozinheiros, entre outros.

Merece ainda ser apreciado o item "trabalho e convivência", que trata de subitens próprios do mundo das tarefas práticas, como “pontualidade/ assiduidade/ responsabilidade/ iniciativa/ produtividade". O trabalho no capitalismo hegemônico anuncia em colossais palavras de ordem que o trabalhador deve ter estes atributos para que se mantenha empregado. Aos que falham em qualquer um, o risco 
do desemprego é maior. A própria competição abre possibilidades para a demissão, pois, se há um trabalhador com descompasso em qualquer dessas esferas, outro com menos descompasso pode assumir seu lugar ao se apresentar como melhor adaptado a esses planos de comportamentos de trabalho.

Essa não era uma questão equalizada entre os coordenadores, pois, embora se saiba que, muitas vezes, os usuários da Saúde Mental podiam ter prejuízo em algumas dessas habilidades, paradoxalmente as oficinas também valorizavam essas características nos oficineiros. Por exemplo, um oficineiro que não conseguia chegar no horário de abertura (que variava entre $7 \mathrm{~h} 00$ e $8 \mathrm{~h} 00$, a depender da oficina) em virtude dos medicamentos sedativos que tomava, mas que tinha iniciativa na composição das peças confeccionadas para serem comercializadas e, por isso, colaborava no aumento do giro financeiro do grupo, era tão valorizado quanto aquele que era pontual na chegada.

$\mathrm{Na}$ atualidade, é solicitado ao trabalhador que ele invariavelmente não se atrase para começar a jornada de trabalho; que se ausente o menos possível; que tenha responsabilidade pela função que exerce; que tenha iniciativa, sendo o mais autônomo que puder; que produza em consonância com as necessidades da empresa. Por isso, claramente os subitens citados foram inspirados nesse modo de trabalho. Entretanto, eles não apontavam que o NOT fosse um lugar de profissionalização, tampouco que seu objetivo fosse o de inserir ou reinserir o oficineiro no mercado; ao contrário, esses subitens eram propositalmente apresentados com outros subitens que indicavam circunstâncias subjetivas do sujeito.

Sobre a computação dos dados, os itens e subitens eram somados conjuntamente. Isso porque era interessante ver que a oficina funcionava pelo envolvimento de muitos sujeitos envolvidos com todo o fazer, cada um com seu ritmo e compasso, sendo lugares que necessitavam de regência pra funcionarem afinadas, mas respeitando também a desafinação que em algum momento surgia. Não necessariamente a regência era realizada pelo coordenador, pois os próprios oficineiros em muitos momentos percebiam a desafinação e se esforçavam para reacomodarem seus fazeres cotidianos com o intuito de que novamente a oficina se afinasse.

$\mathrm{O}$ item denominado de "trabalho e convivência", especialmente, indicava a essência do NOT. Os dois aconteciam conjunta e concomitantemente porque 
acreditávamos que o sentido do trabalho também se dava nas relações entre as pessoas. Aliás, o que propúnhamos aos oficineiros, nós também vivíamos como equipe. Lembro-me um tanto saudosa das muitas manhãs a caminho da fazenda onde funcionava a maioria das oficinas, quando via o sol nascer e pensava em quem gostaria de encontrar para prosear sobre qualquer ideia que tinha tido de um novo produto, ou de uma proposta de intervenção com algum oficineiro, ou para contar que havia feito uma leitura que poderia auxiliar no manejo com algum grupo. Recordo ainda das longas conversas que tinha com muitos colegas no horário do almoço, sentados preguiçosamente no banco embaixo da grande e acolhedora sombra das árvores, matutando sobre os rumos das oficinas. Também há memórias das comilanças na cozinha, quando conversávamos sobre nossos desejos de que muitos bons negócios acontecessem, torcendo para que um cliente fechasse uma grande encomenda que geraria muito trabalho (e os clientes eram generosos, pois nunca faltavam encomendas de bens/serviços), discutindo casos clínicos e tomando um chá. Esses eram momentos informais de muitas boas novas ideias sobre como melhorar as oficinas e de boa convivência entre pessoas diferentes.

\section{Um Processo de Amadurecimento e Fortalecimento do Trabalho da Equipe}

$\mathrm{Na}$ discussão da confecção dessa Planilha, nos questionamos principalmente sobre o porquê estávamos ali fazendo aquelas oficinas e sobre qual era a contribuição de cada profissional naquele fazer. Concluímos nosso movimento de equipe, na tentativa de trabalhar como coletivo que se sustentava, tornou-se visível nesse processo em que todos se apresentaram afinados com os propósitos da RP. Por isso, esse foi um momento profissional muito precioso, pois pude experimentar o que é um trabalho coletivo em que decisões são tomadas e amparadas por um grupo de pessoas com modos de trabalhar, por vezes, muito distintos, mas que se harmonizavam e se respeitavam.

Após o processo de produção da Planilha, a equipe estava mais amadurecida, pois houve uma rede de entrelaçamento colaborativo entre profissionais singulares e o reconhecimento de uma rede constituída de pessoas conectadas pelo comprometimento com o trabalho. Quando o desejo é elemento de comunicação, ele contamina e se produz mais e mais no outro desejo, se tornando mais potente e fortalecendo o grupo. 
Para finalizar, ressalto que $\mathrm{o}$ presente texto, embora fruto de práticas e reflexões de um grupo, só se refere ao meu olhar, ainda que ele seja inevitavelmente e até mesmo desejosamente - contaminado por outros olhares dos outros doze coordenadores de oficinas da época. Meu trabalho também foi feito do trabalho deles, pois foi com eles que aprendi como compor minha própria postura profissional de coordenadora. Com eles aprimorei meu modo de acolher o oficineiro, a ser extremamente cuidadosa com as finanças, a arriscar nos negócios, a me entusiasmar quando discutia o NOT fora dele, a admitir o ócio como momento produtivo do trabalho, a trabalhar até quase a exaustão quando o cotidiano demandava, e é muito provável que em todos eles tenha me inspirado para pensar e escrever esse texto.

Havia também os valiosíssimos encontros com os oficineiros que me emocionavam e me ensinavam sempre sobre diversos modos de vida. Eram encontros repletos de relatos de políticas, dores, ousadias, alegrias, brutalidades, fascínios, caminhos, delicadezas, violências, enfrentamentos, suspiros, rebeldias, tropeços, timidezes, doçuras, afinidades, sofrimentos, encantamentos, entre muitos outros signos que desvelavam suas existências tão singulares. Não parece ser possível ter qualidade no trabalho com pessoas em tratamento na Saúde Mental sem se permitir tocar, se solidarizar e se implicar pelos afetos que são produzidos por e nesses encontros. Cada proposta delirante de compreensão do mundo, cada sentido que atribuíam a determinada experiência, cada insanidade nos gestos e atitudes e cada palavra ou silêncio trocados me apresentavam suas subjetividades e tocavam na minha própria. Assim se fez essa Planilha, assim se movimentava o NOT, assim se constituem as pessoas: ressoando umas nas outras.

\section{Referências}

Alcântara, L. C. (2007). Economia solidária e oficinas de trabalho na saúde mental. In E. E. Merhy \& H. Amaral (Orgs.). Reforma psiquiátrica no cotidiano II (pp.151-161). São Paulo: Hucitec.

Alvarez, J. \& Passos, E. (2009) Cartografar é habitar um território existencial. In E. Passos, V. Kastrup \& L. Escóssia. Pistas do método da cartografia- pesquisa-intervenção $e$ produção de subjetividade (pp.131-149). Porto Alegre: Sulina.

Amarante, P. (2007).Saúde mental e atenção psicossocial ( $3^{\mathrm{a}} \mathrm{ed}$.). Rio de Janeiro: Fiocruz.

Benjamin, W. (2012). O narrador: considerações sobre a obra de Nikolai Leskov. In W. Benjamin. Magia e técnica, arte e política: ensaios sobre literatura e história da cultura (pp.213-240). São Paulo: Brasiliense. 
Brasil. Ministério da Saúde. (2005). Saúde Mental e Economia Solidária: inclusão social pelo trabalho. Brasília, DF: Editora MS.

Campos, G.W.S. (2000).Saúde pública e saúde coletiva: campo e núcleo de saberes e práticas. Ciência e Saúde Coletiva, Rio de Janeiro, 5(2), 219230.Recuperado de https://www.scielo.br/pdf/csc/v5n2/ 7093.pdf.

Cayres, C.O., Domitti, A.C., Carnevalli, M.E. \& Bianchini, V. (2001).O desafio da reabilitação profissional. In A. Harari \& W. Valentini (Orgs.). A Reforma Psiquiátrica no cotidiano(pp.105-112). São Paulo: Hucitec.

Constantino, E.P. (Org).(2007). Percursos da pesquisa qualitativa em Psicologia. São Paulo: Arte e Ciência.

Costa, C.M.\& Figueiredo, A.C. (Orgs.). (2008). Apresentação. In Oficinas terapêuticas em Saúde Mental: sujeito, produção e cidadania (pp. 7 - 10). Rio de Janeiro: Contra Capa Livraria.

Costa-Rosa, A. \& Yasui, S. (2008, janeiro/dezembro). A estratégia atenção psicossocial: desafio na prática dos novos dispositivos de Saúde mental. Saúde em debate, 32 (78/79/80), 27-37. Recuperado de https://www.redalyc.org/pdf/4063/4 06341773003.pdf.

Costa-Rosa, A., Luzio, C.A.\& Yasui, S. (2003). Atenção psicossocial: rumo a um novo paradigma na saúde mental coletiva. In P. Amarante (Org.). Archivos de Saúde Mental e Atenção Psicossocial (pp.13-44). Rio de Janeiro: Nau.
Deleuze, G. (1996). O que é um dispositivo. In G. Deleuze. $O$ mistério de Ariana (pp.83-96). Lisboa: Editora Vegas.

Galletti, M.C. (2004). Oficina em Saúde Mental: instrumento terapêutico ou intercessor clínico? Goiânia: Editora da UCG.

Giacomel, A.E., Ghislene, A.P., Amazarray, M.R. \& Engelman, S. (2003). Trabalho

$\mathrm{e}$ contemporaneidade: o trabalho tornado vida. In T. M. G. Fonseca\& P. G. Kirst. Cartografias e devires: a construção do presente (pp.137148). Porto Alegre: Editora da UFRGS.

Guattari, $\quad$ F.\&Rolnik, S. (2000).Micropolítica: Cartografias do desejo( $\left.6^{\mathrm{a}} \mathrm{ed}.\right)$. Petrópolis: Editora Vozes.

Mairesse, D. (2003). Cartografia: do método à arte de fazer pesquisa. In T. M. G. Fonseca \& P. G. Kirst. Cartografias $e$ devires: $a$ construção do presente (pp. 259271). Porto Alegre: Editora da UFRGS.

Merhy, E. E. (2005). Saúde: a cartografia do trabalho vivo $\left(2^{\mathrm{a}}\right.$ ed.). São Paulo: Hucitec.

Minayo, M.C.S. (2005). Pesquisa qualitativa em saúde. São Paulo: Hucitec.

Minayo, M.C.S. (Org.). (1993). Pesquisa social: teoria, método e criatividade $\left(18^{\mathrm{a}}\right.$ ed.). Petrópolis: Vozes.

Onocko, R. \& Amaral, M. (2002). Cândido Ferreira: experimentando uma mudança institucional. In E. E. 
Merhy \& R. Onocko. Agir em saúde: um desafio para o público (pp.353-371). São Paulo: Hucitec.

Passos, E.\& Barros, R.B. (2009).A cartografia como método de pesquisa-intervenção. InE. Passos, V. Kastrup \& L. Escóssia. Pistas do método da cartografia: pesquisaintervenção e produção de subjetividade(pp.17-31). Porto Alegre: Meridional.

Rauter, C. (2000). Oficinas para quê? Uma proposta ético-estéticopolítica para oficinas terapêuticas. InP. Amarante (Org.).Ensaios: subjetividade, saúde mental, sociedade (pp. 267-277). Rio de Janeiro: Ed. Fiocruz.

Rodrigues, A. (2012). Produção de cuidado em oficinas de geração de trabalho e renda na Saúde Mental. Dissertação de mestrado, Universidade Estadual Paulista, Assis, SP, Brasil.

Rolnik, S. (2014) Cartografia sentimental: transformações contemporâneas do desejo. 2 ed.
Porto Alegre: Sulina, Editora da UFRGS.

Singer, P. (2002). Introdução à Economia Solidária. São Paulo: Fundação Perseu Abramo.

Valentini, W. (2001). Nenhum ser humano será bonsai. In A. Harari \& W. A. Valentini. Reforma Psiquiátrica no cotidiano (pp.1124). São Paulo: Hucitec, 2001.

Ariana Campana Rodrigues possui graduação em Psicologia (2002) e mestrado em Psicologia (2012) pela UNESP (Universidade Estadual Paulista Campus de Assis), onde atualmente é doutoranda no departamento de PósGraduação em Psicologia. Tem experiência na área de Saúde Mental e Coletiva, práticas clínicas e de docência.

E-mail:ondeandas@ hotmail.com

ORCID: http://orcid.org/0000-0003-3566$\underline{5566}$

Submissão: $15 / 01 / 2019$

$1^{\circ}$ avaliação: $12 / 05 / 2020$

Aceite: $27 / 07 / 2020$ 